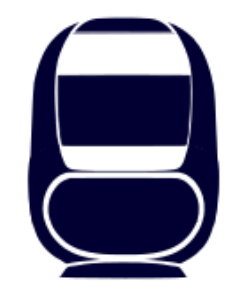

\title{
Raylı Sistemlerde Kullanılan Cer Kancasının Topoloji Optimizasyonuna Uygunluğunun Değerlendirilmesi
}

\author{
Cevat ÖZARPA ${ }^{1}\left(\mathbb{D}\right.$, , Hüseyin BOTSALI ${ }^{1}$ (D), Bahadır Furkan KINACI*2(D) \\ ${ }^{1}$ Karabük Üniversitesi, Mühendislik Fakültesi, Makine Mühendisliği, Karabük, Türkiye \\ ${ }^{2}$ Karabük Üniversitesi, Mühendislik Fakültesi, Raylı Sistemler Mühendisliği, Karabük, Türkiye \\ *bahadirfurkan@outlook.com
}

(Alınış/Received: 29.10.2021, Kabul/Accepted: 29.11.2021, Yayımlama/Published: 31.01.2022)

Öz: Yük ve yolcu taşımacıllığı için raylı sistem taşıtları, çeken ve çekilen araçların birleştirilerek setler halinde kullanılması ile oluşturulmaktadır. Birden fazla vagon ve lokomotifin birleştirilmesi koșum takımları ismi verilen, cer ve fren kuvvetlerini ileten ekipmanlar ile gerçekleştirilir. Sıklıkla birden fazla taşıt birleştirilirken kanca kavramalı, yarı otomatik ve tam otomatik koşum takımları kullanılmaktadır. Koşum takımları taşıtlar arası statik ve dinamik yüklere maruz kalması ve özellikle çeken ve çekilen araçlar arasında hareketin direkt aktarılması için en kritik ekipman olması açısından özel incelenmesi gereken ekipmanlar olarak karşımıza çıkmaktadır. Son yıllarda eklemeli imalat benzeri üretim metotlarında gerçekleşen gelişmeler, geleneksel metotlarla üretilemeyecek geometrik ve yapısal farklılığa sahip malzemelerin üretilmesine olanak sağlamıştır. Geometrik ve yapısal olarak üretim kolaylığı malzeme üretiminde ağırlık, hacim, doğal frekans, yer değiștirme ve reaksiyon kuvvetlerine göre en uygun tasarımların yapılmasına imkân tanımaktadır. Belirtilen en uygun geometrik ve yapısal tasarımlar topoloji optimizasyonu gibi yapısal optimizasyon çözümleri kullanılarak gerçekleştirilebilmektedir. Çalışmamızda kanca kavramalı koşum takımında yüklere direkt maruz kalan cer kancası üzerinde yoğunluk tabanlı yöntemden üretilmiş olan simp yöntemi kullanılarak topoloji optimizasyonu gerçekleştirilmiştir. Ekipmanın optimizasyon öncesi statik analizleri yapılıp, yeterli iterasyon kullanılarak topoloji optimizasyonu gerçekleştirilmiş ve ortaya çıkan grafik model tersine mühendislik yapılarak katı modele çevrilmiştir. Uygulama sonucu $100 \mathrm{kN}$ kuvvete maruz kaldığında yeterli dayanımı sağlamaya devam eden yeni katı modelin \%8,33 oranında ağırlık kazanımı sağladığı tespit edilmiştir. Yapılan çalışma ile cer kancası tertibatının topoloji optimizasyonu yapılmasına uygun olma durumu değerlendirilecektir.

Anahtar kelimeler: Cer Tertibatı, Sonlu Elemanlar Analizi, Topoloji Optimizasyonu, Yoğunluk Tabanlı Yöntem, Simp Yöntemi.

\section{Evaluation of the Suitability of Draw Hook Used in Rail Systems for Topology Optimization}

\begin{abstract}
Rail system vehicles for freight and passenger transportation are formed by combining tractive and hauled stocks and using them in sets. When combining more than one vehicle, hook clutch, semiautomatic, and fully automatic coupling are used. Coupling emerges as equipment that needs to be specially examined in terms of being exposed to static and dynamic loads between vehicles and being the most critical equipment for the direct transfer of movement, especially between towed and towed vehicles. In recent years, developments in production methods like additive manufacturing have enabled the production of materials with geometric and structural differences that cannot be produced with traditional methods. Geometrically and structurally, the ease of production allows the most appropriate designs to be made in the material produced according to weight, volume, natural frequency, displacement, and reaction forces. The specified optimal geometric and structural designs can be realized by using structural optimization solutions such as topology optimization. In our study, topology optimization was carried out using the simp method, which was produced from the density-based method, on the drawbar hook, which is directly exposed to loads in the hook coupling. Before the optimization, static analysis of the equipment were made, topology optimization was carried out using sufficient iterations, and the resulting graphic model was converted into a solid model by reverse engineering. As a result of the application, it has been determined that $8.33 \%$ weight gain can be achieved in the new solid model, which continues to provide sufficient
\end{abstract}

Atıf için/Cite as: C. Özarpa, H. Botsalı, B.F. Kınacı, "Raylı sistemlerde kullanılan cer kancasının topoloji optimizasyonuna uygunluğunun değerlendirilmesi,” Demiryolu Mühendisliği, no. 15, pp. 112, Jan. 2022. doi: 10.47072/demiryolu.1016373 
strength when exposed to a force of $100 \mathrm{kN}$. With the study, the suitability of the traction hook assembly for topology optimization will be evaluated.

Keywords: Draw Hook, Finite Element Analysis, Topology Optimization, Density Based Method, Simp Method

\section{Giriş}

Raylı sistem taşımacılığı gelişen endüstrileşme, ulaşım metotları içerisindeki güvenliği ve taşıma maliyeti etkinliği benzeri sebepler ile gelişmekte olan bir taşıma metodudur. Raylı sistem taşıtları yük ve yolcu taşımak amacı ile birleşik setler ve birden fazla çeken, çekilen taşıtlardan oluşan setler olarak hizmet vermektedir. Diziler halinde çalışmayı sağlaması, cer ve fren kuvvetlerinin taşıtlar arasında iletilmesi için koşum takımları kullanılmaktadır. Gerekli bağlantıların sağlanabilmesi için, sıklıkla kanca kavramalı, yarı otomatik ve tam otomatik koşum takımları kullanılmaktadır. Tüm benzer yapılarda olduğu gibi raylı sistem yapılarında da mekanik sistem elemanları yoğun şekilde yorulma ve aşınmalara maruz kalabilmektedir. Mekanik yorulma ömürleri ve aşınma dayanımları dışında üretim yöntemi kriterleri, malzeme miktarları sistemlerin tasarımlarında önemli parametreler olarak karşımıza çıkabilmektedir. Genellikle tasarlanan sistemlerin en düşük hacimle en iyi dayanımı sağlaması beklenir. Belirtilen şartların sağlanması için üretim safhasına geçmeden önce sonlu elemanlar analizi yazılımları aracılığıyla yapısal mukavemet testleri ve topoloji optimizasyonu benzeri uygulamalar yapılmaktadır. Yapısal optimizasyon çalışmalarından olan topoloji optimizasyonu ile elde edilen ve geometrik olarak üretimi zor olan modeller eklemeli imalat gibi ileri imalat teknolojileri sayesinde üretilebilmektedir. Topoloji optimizasyonu uygulamaları gerçekleştirildikten sonra incelenen modellerin geometrik, ağırlık, dayanım ve doğal frekans gibi parametrelerinde üretilebilirlik ölçeğinde iyileştirmelerin ortaya çıkması ve bunun neticesinde ilave ortaya çıkan üretim zorluklarının göze alınması gerekmektedir. Topoloji optimizasyonunun uygulanabilmesi için geometrik, ağırlık, dayanım ve doğal frekans gibi iyileştirmelerinin ortaya çıkacak olan üretim zorluklarının göze alınması için yeterli seviyede olması gerekmektedir.

Literatürde yapılan çalışmalar incelendiğinde raylı sistem taşıtlarında kullanılan komponentler ile ilgili oldukça az çalışma olduğu, raylı ulaşım ile ilgili yapılan sınırlı çalışmaların ise çoğunlukla taşıt mekanik aksamlarından ziyade demiryolu ve zemini hakkında olduğu görülmüştür. Varandas vd. [1] sonlu elemanlar analizi ile doğrusal olmayan davranışları dikkate alarak demiryolu hatlarının uzun vadeli davranışını incelemiş, Ferdous vd. [2] sonlu elemanlar analizi yardımıyla yenilikçi bir kompozit demiryolu traversi geliştirmiş ve incelemiş, Kaewunruen vd. [3] sonlu elemanlar analizi ile demiryolu raylarının hareketli tren yüklerine dinamik tepkilerini incelemiştir ve Yazdani vd. [4] yüksek hızlı trenlere maruz kalan demiryolu düz beton kemer köprülerini sonlu elemanlar analizi ile incelemiştir. Taşıt bileşenleri ve mekanik davranışları ile ilgili de birtakım çalışmalar literatürde mevcuttur. Yang vd. [5] demiryolu taşıtlarının çarpışma bölgesini, Srivastava vd. [6] yük treni boji desteğini, Kim vd. [7] ise demiryolu taşıtlarının körüklü bağlantılarını sonlu elemanlar analizleri ve topoloji optimizasyonu kullanarak incelemişlerdir. Ayrıca literatürde yapılan genel araştırmada bir modelin yerini topolojik olarak optimize edilmiş yenisinin alması için en az \%20 oranında kütlesel kazanım sağlanmasının tasarım ve üretim akışının değişmesi, yeni üretim yöntemleri uygulanması gibi ortaya çıkacak zaman ve maliyet giderlerini karşılamak için gerekli görüldüğü gözlenmiştir [8]-[10]. Bu oran, optimizasyonun uygulanacağı malzemeye, geometriye ve kullanım alanına göre daha küçük değerlerde kabul edilebilir. $\mathrm{Bu}$ durumun yalnızca sorunsuz işleyen yapılarda kütlesel kazanım hedeflenen çalışmaları kapsadığı, dayanımı arttırmak veya doğal frekansı iyileştirmek gibi hedeflerle gerçekleştirilen çalışmalarda kütlesel kazanım aranmayabileceği unutulmamalıdır. Yapılan çalışmada raylı sistem araçlarında kullanılan kanca kavramalı cer takımı, standartlardaki verilere göre malzeme özellikleri ve yükler altında analiz edilip topoloji optimizasyonu uygulaması 
gerçekleştirilmiş ve geometrik olarak değişiklik yapılarak üretim yöntemi değişiminin gerekli olup olmadığg tespit edilecektir.

\subsection{Raylı sistemlerde kullanılan koşum takımları}

Raylı sistem taşıtları, birleşik taşıtlar ve birden fazla çeken, çekilen araçlardan oluşan setler olarak kullanılmaktadır. Birlikte kullanılan çeken ve çekilen araçlar dizileri tren olarak isimlendirilmektedir. Tren dizisi içerisinde araçların birlikte hareket edebilmesi, cer ve fren kuvvetlerinin aktarılması koşum takımları ile mümkün olmaktadır. Koşum takımları bu görevlerinin yanı sıra, özelliklerine göre taşıtlar arasında çarpışmayı önleyebilmek için tampon görevi, araçlar arası elektriksel bağlantı sağlanması ve hava bağlantıları benzeri görevleri yerine getirmektedir. Raylı sistem setlerinde genellikle kanca kavramalı, yarı otomatik ve tam otomatik koşum takımı olmak üzere 3 ayrı yapıda koşum takımı kullanılmaktadır. Kanca kavramalı koşum takımı en basit yapıda olan taşıtlar arası bağlantı ve ayrılma işlemleri bir personel tarafından gerçekleştirilen koşum takımlarıdır. Yarı otomatik koşum takımı bağlantı işlemi 2 taşıtın birbirine yaklaşması sonucu otomatik olarak ve ayrılma işlemi bir personel tarafından gerçekleştirilen ayrıca taşıtlar arası tampon görevi gören koşum takımlarıdır. Tam otomatik koşum takımlarında ise bağlantı işlemi 2 taşıtın birbirine yaklaşması sonucu otomatik olarak gerçekleşmekte ve ayrılma işlemi de taşıt içerisindeki butonlar ile otomatik olarak gerçekleşmektedir. Ayrıca tam otomatik koşum takımları araçlar arası tampon görevi, elektriksel ve hava bağlantılarının gerçekleştirilmesine olanak sağlamaktadır. Şekil 1'de kanca kavramalı, yarı otomatik ve tam otomatik koşum takımları gösterilmiştir [11]-[13].
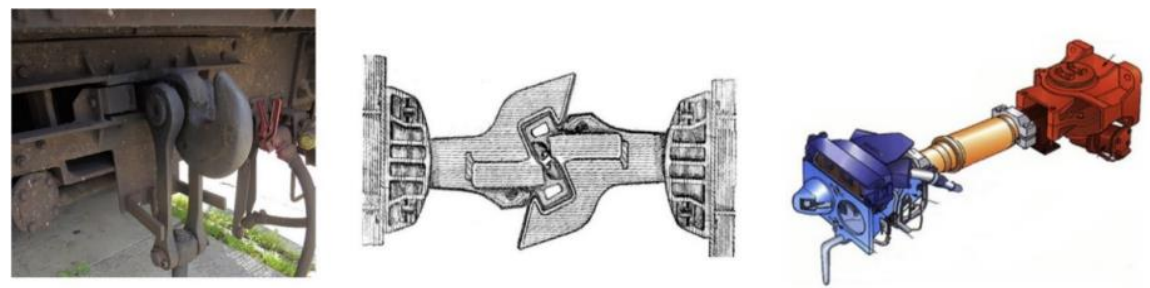

Şekil 1. Kanca kavramalı, yarı otomatik ve tam otomatik koşum takımı türleri [11]-[13]

\subsection{Kanca kavramalı cer takımı}

Raylı sistem taşıtlarının birlikte kullanılabilmesi için gerekli olan koşum takımlarından kanca kavramalı cer takımı, yaygın olarak kullanılmaktadır. Kanca kavramalı cer takımı bağlantı ve ayrılma işlemi bir personel tarafından gerçekleştirilen yapıya sahiptir. Şekil 2'de kanca kavramalı cer takımının temel bölümleri gösterilmiştir.

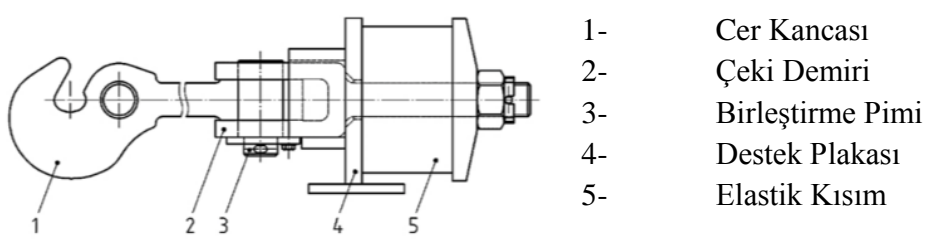

Şekil 2. Temel cer kancası yapısı [11]

Tren hareketleri ile kanca kavramalı cer takımı üzerinde çeşitli kuvvetler birikir. Biriken bu kuvvetler kanca kavramalı cer takımı üzerinde sönümlemeye maruz kalır. Denklem 1'de ortaya çıkan bu sönümlemenin yüzdelik olarak hesaplaması verilmiştir. Sönümleme miktarı emilen enerjinin depolanan enerjiye oranıdır [11].

$$
d \%=\frac{W a}{W e} \cdot 100 \%
$$




\subsection{Sonlu elemanlar analizi}

Sonlu elemanlar yöntemi kısmi diferansiyel denklemlerin nümerik çözümü şeklinde tanımlanabilir. Genel mantığı fiziksel sistemlerin matematiksel olarak ifade edilmesidir. $\mathrm{Bu}$ yöntem sayesinde çözüm olabildiğince basite indirgenir hatta çözülmesi imkânsız problemler bile çözülebilir hale getirilir. $\mathrm{Bu}$ yöntemde gerçek sistemin varsayımlar ve yaklaşımlar ile basitleştirilmesi esas alındığı için kesin doğru sonuç vaad etmez [14]. Ancak 60 yılı aşkın süredir yapısal mukavemet analizleri için kullanılmakta olan sonlu elemanlar yöntemi geçirdiği teknolojik gelişim ile bugün \%98'e kadar doğruluk sağlayabilen yöntemler olarak karşımıza çıkmaktadır. Bu ciddi oran ile sonlu elemanlar analizleri mühendislik problemlerinin çözümünde ciddi kolaylıklar sağlamakta, prototip üretimini en aza indirmekte ve doğrudan üretime geçebilme hızına büyük katkı yapmaktadır. Günümüzde pek çok paket program içerisinde kullanılabilen sonlu elemanlar analizi ile doğrusal ve doğrusal olmayan statik ve dinamik problemler çözülebilmektedir [15]. Fiziksel sistemler genellikle doğrusal olmayan problemler içermektedir. Benzer şekilde zamandan tamamen bağımsız olması da genellikle mümkün değildir. Ancak sonlu elemanlar analizinin temelinde fiziksel sistemi olabildiğince basitleştirmek yer aldığ için belirli varsayımlar yaparak çoğu sistem doğrusal ve statik olarak kabul edilebilir. Bu durum uygulama adımlarından, çözücü işlemci gereksiniminden ve çözüm süresinden oldukça fazla tasarruf sağlayacak önemli bir basitleştirmedir [16]. Bir sistemin doğrusal olmayan bir probleme dönüşmesinde en büyük etkenlerden biri plastik şekil değişimine maruz bırakacak kadar büyük deformasyona uğramasıdır. Bu tür durumlarda problemi doğrusal olarak çözmek deformasyon miktarı arttıkça sonucu daha yanlış bir yere götürmektedir. Bu bilgiler ışığında doğrusal olarak çözülmüş bir problemin ancak plastik deformasyonun başladığı noktaya, yani akma dayanımına kadar hesaplamaları doğru şekilde yapabildiği söylenebilir. Burada yapılacak statik varsayımı ise matematiksel formülde zamana bağlı tüm değişkenleri devre dışı bırakacağı için hesaplama süresi ve kolaylığı açısından büyük fayda sağlayacaktır. Bu varsayımda bulunabilmek için kuvvetin uygulandığı süreyi ve yapının ilk doğal frekansının bilinmesi gerekmektedir. Uygulanan kuvvetin frekansı yapının ilk doğal frekansının 1/3'ünden daha az ise sistem statik olarak kabul edilebilmektedir [17].

\section{Metot}

Bu çalışma kapsamında yapılan araştırmada, raylı sistem kanca kavramalı cer takımının en kritik parçalarından olan cer kancası, sonlu elemanlar yöntemi ile yapısal mukavemet analizine tabi tutulmuştur. Elde edilen veriler ile cer kancası ekipmanı için topoloji optimizasyonu çalışması gerçekleştirilmiştir. Yapılan çalışmalar ile elde edilen sonuçların yeterliliği, üretilebilirliği ve verimliliği değerlendirilmiştir. Çalışmada sonlu elemanlar analizi uygulamaları gerçekleştirilerek statik analizler yapılıp yoğunluk tabanlı yöntemden türetilen simp yöntemi ile topoloji optimizasyonu gerçekleştirilmiştir. Kullanılan yöntemler ve bu yöntemlerin uygulanış şekilleri başlıklar altında detaylandırılmaktadır.

\subsection{Doğrusal statik analiz}

Bir sonlu elemanlar analizine başlamadan önce ilk olarak geometri basitleştirme yapmak tavsiye edilir. Bu aşamada kritik öneme sahip olmayan detaylar düzlenir, delik içleri doldurulur. Böylece sonlu elemanlar ağı ideal şekilde oluşturulabilir ve bu sayede analiz sonucunda daha doğru veriler elde edilebilir. Basitleştirme işlemi tamamlandıktan sonra malzeme özellikleri tanımlanır. Doğrusal statik analizler için elastikiyet modülü ve poisson oranı tanımlamak yeterlidir. Yer çekimi ivmesi analizde kullanılacaksa yoğunluk da ayrıca tanımlanmalıdır. Sonraki işlem çoklu gövde analizlerine mahsustur. $\mathrm{Bu}$ analizlerde sonlu eleman ağı oluşturulmadan önce temas ilişkilerinin belirtilmesi gereklidir. Bu ilişkileri tek tek tanımlamak yerine genel temas ilişkisi vermek de güncel yazılımlarda gayet başarılı sonuçlar sunmaktadır. Doğru yerde kullanımında 
çözüm için oldukça fayda sağlayan kabuk ve kiriş gibi gövde elemanlarının seçimi de ağ oluşturulmadan yapılmalıdır. Bu işlemlerin tamamlanmasıyla sonlu elemanlar analizinin en hayati aşaması denilebilecek sonlu eleman ağı oluşturulabilir [18]. Katı gövdeler için altı yüzlü ve dört yüzlü, kabuk ve kiriş gibi iki boyutlu gövdeler içinse dörtgen ve üçgen gibi çok sayıda çeşitli ağ elemanları en iyi ağ örgüsünü elde etmek üzere seçilebilir. Sonlu eleman ağının birinci veya ikinci mertebeden bir polinoma göre oluşması tercih edilebilmektedir. İkinci mertebeden ağ yapısında daha fazla düğüm noktası oluşacağı için daha hassas sonuçlar elde etmek mümkün hale gelmektedir. Seçenek olarak sunulan adaptif ağ ise modelin tamamına küçük boyutlu ağ oluşturmak yerine daha büyük boyuttan başlayarak kademeli olarak ağı inceltmeye imkân tanır. Böylelikle eleman sayısı ve dügüm noktası azalarak çözüme ulaşmak kolaylaşmaktadır [19]. A $\breve{g}$ oluşturulduktan sonra matematiksel olarak sisteme dahil edilecek sınır koşulları tanımlanır. Bunların en önemlileri yapının rijit cisim dinamiğine uğramaması için tanımlanması gereken sabitlemeler ve sistemin çalışma prensibinde yer alan yükleme durumlarıdır. Bu aşamaları gerçekleştirerek ön işlemler tamamlanmış olur ve sonlu elemanlar analizi çözdürülebilir. Sonlu elemanlar yönteminin basit işlemlerinde kullanılabilen seyrek matris metodu büyük sistemlerde çok uzun vakit aldığı için sonlu elemanlar analizi paket programları genellikle Newton-Raphson metodu kullanarak nümerik çözüm elde eder. Yapılan tüm basitleştirmeler ve çözüm yönteminin iteratif olması nedeniyle kesin doğru sonuç yerine \%98 doğruluk temin edilir [20].

$$
\{F\}=[K] \cdot\{u\}
$$

Doğrusal statik sonlu elemanlar analizinin çözümünde kullanılan denklem en temel haliyle Denklem 2'deki gibi ifade edilir. Burada $\mathrm{F}$ sisteme uygulanan kuvvet matrisini, $\mathrm{K}$ içerisinde Young modülü, atalet momenti, kesit alanı gibi malzemesel ve geometrik özellikleri barındıran rijitlik matrisini ve $\mathrm{u}$ ise yer değiştirme matrisini temsil etmektedir. Doğrusal statik yapısal analizlerde bilinmeyen, yer değiştirmedir ve analiz sonucunda bu değer elde edilmiş olur. Bunun neticesinde gerilme ve gerinim gibi istenilen diğer değerler matematiksel formüller ile üretilerek karşımıza çıkmaktadır. Sonlu elemanlar çözücüsü ağ örgüsünün her bir düğüm noktası için değerleri hesaplar ve her elemanın ortak düğüm noktalarındaki değerleri interpolasyon yaparak eleman değerlerini ortaya çıkarır. Yukarıda bahsedildiği gibi kritik değerlerin oluştuğu bölgeleri daha hassas ölçümleyebilmek için bu bölgelerin sonlu eleman sayısı artırılabilir. Yeterli ağ örgüsünü elde ettiğimizi anlamanın bir yöntemi nispeten kaba bir ağ eleman boyutu ile analizi çözdürüp daha sonra aşamalı bir şekilde incelterek sonuçların yakınsamasını gözlemlemektir. Daha fazla yakınsamadığını fark edildiğinde ağ örgümüzü yeterli olarak görebiliriz. Bunun dışında ağ kalitesini ölçmek için gözlemlenebilecek kalite parametreleri de sonlu elemanlar yazılımlarında mevcuttur [21]. Analiz sonuçları gözlemlenirken reaksiyon kuvvetleri de izlenebilmektedir. Sabitleme bölgelerinde oluşan reaksiyon kuvvetlerinin sisteme uygulanan kuvvetleri karşılayıp karşılamadığı analizin doğru kurgulanıp doğru sonuçlar verdiğine dair önemli ipuçları sunar. Doğrusal statik analiz sonuçlarının yorumlanmasında dikkat edilmesi gereken bir diğer husus ise çözümün yalnızca elastik bölgede doğru sonuçlar sağlayabildiğidir. Çünkü büyük deformasyon olarak adlandırılan yapının plastik şekil değişimine maruz kalacağı ölçüde deformasyona uğramayacağını varsayarak analiz gerçekleştirilmiştir. Bu nedenle analiz sonuçları akma noktasına kadar olan bölgede yorumlanmalı ve kopma, kırılma gibi kalıcı deformasyonların burada gözlemlenemeyeceği bilinmelidir. Okunabilecek en anlamlı sonuçlardan biri sistemin akmaya karşı ne oranda emniyetli olduğudur. Sünek malzemelerde emniyet katsayısı akma dayanımının yapıda oluşan en yüksek gerilmeye bölümü ile elde edilir [22].

\subsection{Topoloji optimizasyonu}

Boyut, şekil ve topoloji optimizasyonlarını içeren yapısal optimizasyon yaklaşık 100 yıllık bir maceraya sahiptir. Topoloji optimizasyonu ilk tasarımdan tümüyle bağımsız elde edilebildiği için diğer iki metoda kıyasla kütle ve dayanım bakımından en verimli sonuçları verir [23]. Fakat bu 
yöntemle elde edilmiş geometrilerin geleneksel yöntemlerle üretilmesi oldukça zor olduğu için yakın zamana kadar tasarım ve üretim alanlarında beklenen etkiyi gösterememiştir. Son 20 yıllık süreçte eklemeli imalat alanındaki gelişmelere paralel olarak topoloji optimizasyonu alanında da pek çok çalışma yapılmış ve hızlı bir gelişim göstermiştir [24]. Geleneksel imalat için topoloji optimizasyonu çalışmasında geometri, ilk optimizasyon sonucu elde edildikten sonra imalat için tasarım kriterlerine göre yeniden tasarlanır. $\mathrm{Bu}$ geometri, optimize edilmiş değerlerden sapabileceği için yeniden optimizasyona tabi tutulur. Genellikle bu tekrarlı sürecin sonunda çok verimli sonuçlar sağlanamaz [25]. Eklemeli imalat için tasarım kriterleri, tasarım kısıtlamalarını en aza indirgediği için en optimum sonuçlarla üretime olanak sağlar. Bu yönüyle eklemeli imalat topoloji optimizasyonu alanında yeni bir çağ açmıştır [26]. Topoloji optimizasyonu, belirli kısıtlamalara bağlı olarak bir geometrinin belirli bir hacimdeki yerleşiminin matematiksel bir formül aracılığıyla en verimli halini bulmaya çalışmaktır. Farklı parametreleri baz alarak oluşturulmuş çeşitli optimizasyon formüllerine dayanan topoloji optimizasyonu türleri mevcuttur. Bunlardan başlıcaları homojenizasyon yöntemi, seviye seti yöntemi, faz alanı yöntemi, evrimsel yapısal optimizasyon ve yoğunluk tabanlı yöntem olarak sayılabilir [27]. Topoloji optimizasyonu çalışmasında en önemli adımlardan biri hedefleri ve sınırlamaları doğru belirlemektir. Her topoloji optimizasyonu türü farklı formül ile çözüme ulaşsa da bu adım tüm yöntemler için ortak olarak gerçekleşir. Topoloji optimizasyonu parametrik bir işlem olmadığ i için sınırlamalar belirlemememiz halinde beklenenin çok uzağında ve kullanışsız bir geometri elde edilmesi büyük olasıl1ktır. Bu nedenle özellikle sabitleme veya yük uygulama gibi nedenlerle sabit kalmas1 gereken bölgelerin belirlenmesi önemlidir. Ayrıca hacim, doğal frekans, yer değiştirme ve reaksiyon kuvveti gibi değerleri de sabit kalması veya belirli bir aralıkta kalması yönünde sınırlama olarak belirlenebilir. Optimizasyon çalışmasının amacına ulaşabilmesi içinse istenen oranlarda hacmi azaltmak, rijitliği artırmak, yer değiştirmeyi azaltmak, ilk doğal frekansı artırmak veya reaksiyon kuvvetini azaltmak gibi hedefler belirlenebilir [28].

\subsection{Yoğunluk tabanlt yöntem ve simp yöntemi}

Topoloji optimizasyonunun 30 yıllık evriminde çeşitli yöntemler ortaya çıkmıştır. Bu alandaki çalışmalar yoğun bir şekilde devam etmekte ve bu yöntemlerin çoğunda yeni gelişmeler meydana gelmektedir. $\mathrm{Bu}$ yöntemler arasında en önde gelen ikisi evrimsel yapısal optimizasyondan türetilmiş olan çift yönlü evrimsel yapısal optimizasyon (Bi-directional Evolutionary Structural Optimization (BESO)) ve yoğunluk tabanlı yöntemden türetilmiş olan cezalandırmalı katı izotropik malzemedir (Solid Isotropic Material with Penalization (SIMP)) [29]. Simp metodu sonlu elemanlar tabanlı kullanıma en uygun yöntem olarak öne çıkmış ve pek çok sonlu elemanlar yazılımına entegre edilmiştir. Simp metodunda 0 boş elemanı ve 1 katı elemanı temsil edecek şekilde sonlu eleman modelinde her elemana yoğunluk değerleri atanır ve optimizasyon işlemi elastikiyet modülüne bağlı bir fonksiyon ile iteratif olarak gerçekleştirilir [30]. Simp metodu popülerliği ve kullanışl1lığı nedeniyle çok fazla akademik çalışmalar yapılmış ve sonlu elemanlar analizi yazılımları ile daha verimli hale gelmesi için geliştirilmiştir. Özellikle sonlu elemanlar analizi yazılımları ile uyumlu hale gelmek üzere geliştirmeler yapılmıştır. Mevcut kullanımda optimizasyon için matematiksel fonksiyonun kararlı bir şekilde işleme alınabilmesi ve sonlu elemanlar analizinin doğru bir şekilde çözülebilmesi için yoğunluk değerinin 0'dan farklı alınması gereklidir. Eleman yoğunluk değeri $\rho$ ile ifade edilir. En küçük boş elemanı ise $\rho_{\text {min }}$ değeri temsil eder. Bu değerin neden 0'dan farklı verilmesi gerektiği, Denklem 3'te verilen simp metoduna göre rijitlik matrisi hesabından anlaşılabilir. Boş eleman yerine 0 değeri verilmesi halinde formülasyonda kullanılan denklemden anlamlı sonuçlar almak zorlaşacaktır. Malzeme yoğunluğunun elemanlar arasında değişiklik göstermesi nedeniyle elastikiyet modülü de değişiklik göstermektedir. Her eleman için elastikiyet modülü Denklem 4'teki gibi hesaplanmaktadır. Denklemden anlaşıldığı gibi cezalandırma faktörü p, her elemanı boş veya katı eleman olmaya zorlamakta, ara değerlerdeki yoğunluğa sahip elemanların etkisini azaltmaktadır. Belirlenen hedefe ve kısıtlamalara göre kullanılan farklı denklemler de mevcuttur. Simp metodu 
algoritması yinelemeli bir işlemle verilen hedefe ulaşmaya çalışır. $\mathrm{Bu}$ yinelemeler hedef fonksiyonlarındaki değişimler istenen yakınsama kriterlerini sağlayana kadar devam eder [31].

$$
\begin{gathered}
K=\sum_{e=1}^{N}\left[\rho_{\min }+\left(1-\rho_{\text {min }}\right) \rho_{e}^{p}\right] K_{e} \\
E=E_{0} \cdot \rho^{p}
\end{gathered}
$$

Simp metodu Ansys, Simulia Abaqus, Altair Hyperworks, SW Simulation gibi önde gelen sonlu elemanlar analizi yazılımlarında kullanılmaktadır. Geçmiş çalışmalardan cezalandırma faktörü $p$ için en iyi sonucu 3 değerinin verdiği saptandığı için genellikle varsayılan olarak bu değer tanımlanmakta isteğe göre farklı değerler kullanılabilmektedir. Cezalandırma faktörü p'nin farklı değerleri için interpolasyon şeması Şekil 3'de verilmiştir. Bu şema Denklem 4 kullanılarak $E / E_{0}$ ' 1 n $\rho^{p}$ 'ye göre durumunu göstermektedir. Simp metodunda verimli sonuçlar alabilmek için eleman boyutlarının olabildiğince küçük olması gerekmektedir. Tavsiye edilen değerler doğrusal bir statik analizde kullanılan ideal değerlerin yaklaşık dörtte biridir. Ayrıca elemanlar arası hassasiyetin sağlanabilmesi için en/boy oranının da 1,1'i geçmemesi önemle tavsiye edilmektedir [32]-[34].

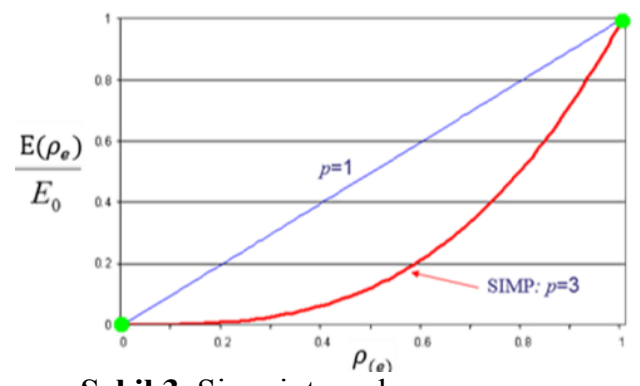

Şekil 3. Simp interpolasyon şeması

\subsection{Uygulama detayları}

Yapmış olduğumuz çalışmada raylı sistem taşıtlarının koşum takımlarından olan kanca kavramalı cer takımının, cer kancası parçası SW Simulation sonlu elemanlar analizi paket programı kullanılarak doğrusal statik analiz ve topoloji optimizasyonu uygulamaları ile incelenmiştir. İncelenecek malzeme seçilirken, EN 15566 "Cer kancası tertibatlı koşum takımı standardı" malzeme seçiminde EN 10083 standardına göre malzeme seçimi yapılması gerektiğini belirtilmiştir [35]. Çalışmamızda, EN 10083 standardının ortaya koymuş olduğu malzeme seçimi parametreleri sonucu dökme karbon çelik malzemesi tercih edilmiştir [36]. Tablo 1'de dökme karbon çeliğinin doğrusal statik analiz ve topoloji optimizasyonu için gerekli olan malzeme parametreleri verilmiştir.

Tablo 1. Dökme karbon çeliği malzeme özellikleri

\begin{tabular}{lc}
\hline Elastikiyet Modülü $(\mathrm{E})$ & $2 \times 10^{5} \mathrm{MPa}$ \\
Poisson Oranı $(\mathrm{v})$ & 0,32 \\
Akma Dayanımı $(\sigma \mathrm{A})$ & $248,17 \mathrm{MPa}$ \\
Yoğunluk $(\rho)$ & $7800 \mathrm{~kg} / \mathrm{m}^{3}$ \\
\hline
\end{tabular}

Optimizasyon öncesi ve sonrası yapılan statik analizlerin sonuçlarının doğru karşılaştırmayı sağlayabilmesi için tüm analizlerin matematik modelleri malzeme, sabitleme ve yükleme koşulları aynı şekilde tanımlanmıştır. Sadece topoloji optimizasyonu uygulaması için sonlu eleman ağı daha ince ve geçiş oranı daha düşük şekilde oluşturulmuştur. Bunun gerekçeleri 
yoğunluk tabanlı yöntem başlığı altında açıklanmıştır. Sabitleme ve yükleme koşulları ise gerçek çalışma mantığına uygun ve doğru sonuçları verecek şekilde tanımlanmıştır. Yükleme değerini hesaplarken parçanın akmaya karşı dayanım oranını ifade eden emniyet katsayısını 2 kat sağlaması baz alınmış ve $100 \mathrm{kN}$ değeri belirlenmiştir. Standartlarda cer kancası dayanım kriteri $1000 \mathrm{kN}$ olarak verilmesine karşın bu uygulamada sistemin tek bir parçası incelendiği için bu şekilde kabul yapılmıştır [37]. Topoloji optimizasyonu çalışmaları da 2 emniyet katsayısını sağlayarak kütleyi düşürmek hedefiyle gerçekleştirilmiştir. Topoloji optimizasyonları gerçekleştirilirken parça xy düzlemine göre simetrik olduğu için bu düzleme göre simetrik olması imalat kısıtı olarak eklenmiştir. Şekil 4'te sonlu eleman modeli ve sınır şartları, tablo 2'de ise sonlu eleman modelleri ile ilgili gerekli tanımlamalar gösterilmiştir [38].

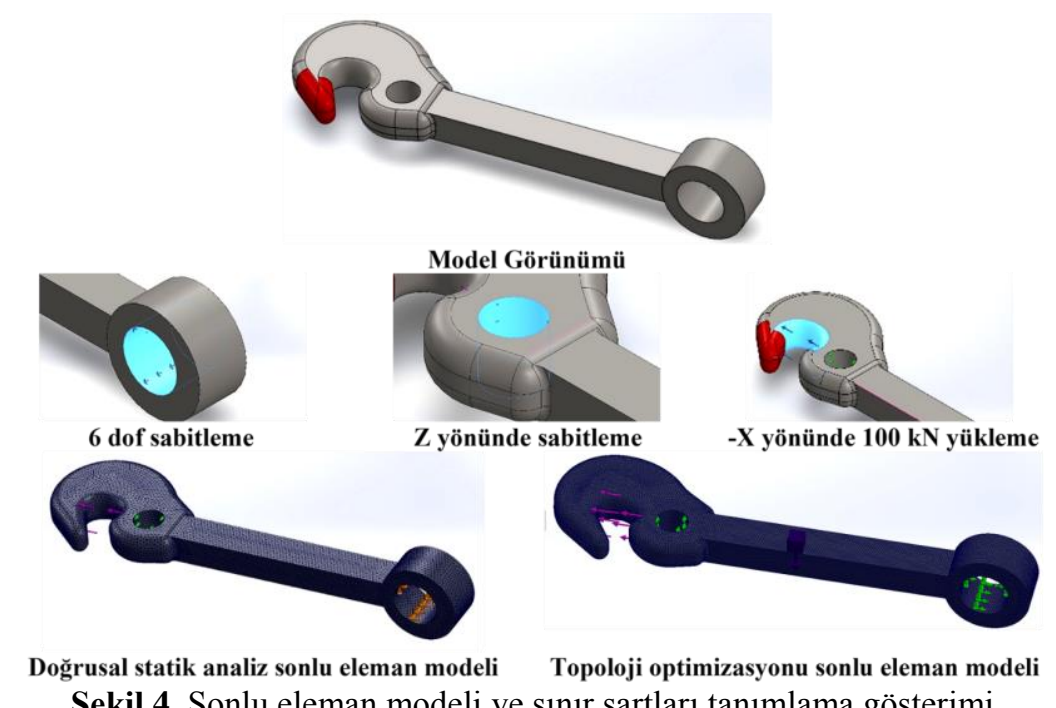

Şekil 4. Sonlu eleman modeli ve sınır şartları tanımlama gösterimi

Tablo 2. Sonlu eleman ağı detayları

\begin{tabular}{|c|c|c|c|}
\hline \multicolumn{2}{|c|}{ Doğrusal statik analiz sonlu eleman ağ } & \multicolumn{2}{|c|}{ Topoloji optimizasyonu sonlu eleman ağ1 } \\
\hline Ağ tipi & Katı eleman & A $\breve{g}$ tipi & Katı eleman \\
\hline A ğ oluşturucu & $\begin{array}{l}\text { Karışık eğirilik } \\
\text { tabanlı ağ }\end{array}$ & Ağ oluşturucu & $\begin{array}{l}\text { Karışık eğirilik } \\
\text { tabanlı ağ }\end{array}$ \\
\hline Ağ kalitesi & 2.mertebe eleman & A $\breve{g}$ kalitesi & 2.mertebe eleman \\
\hline En küçük eleman boyutu & $4 \mathrm{~mm}$ & En küçük eleman boyutu & $3 \mathrm{~mm}$ \\
\hline En büyük eleman boyutu & $6 \mathrm{~mm}$ & En büyük eleman boyutu & $4 \mathrm{~mm}$ \\
\hline Eleman boyutu geçiş oranı & 1,4 & Eleman boyutu geçiş oranı & 1,1 \\
\hline Toplam eleman sayısı & 147518 & Toplam eleman sayısı & 418391 \\
\hline Toplam düğüm sayısı & 214409 & Toplam düğüm sayısı & 596093 \\
\hline
\end{tabular}

\section{Bulgular}

Doğrusal statik analiz etüdünün sonuçlanmasının ardından statik analizlerin öncelikli hesapladığı değer olan yer değiştirme miktarına ve sıklıkla tercih edilen gerilme hesaplama yöntemi olan von mises gerilmesine bakılmıştır. Emniyet katsayısı, von mises gerilmesinin akma mukavemetine oranı olarak hesaplanmıştır. Ardından diğer üretim kısıtları ile birlikte bu emniyet katsayısı değeri kısıt olarak belirlenerek topoloji optimizasyonu etüdü gerçekleştirilmiş ve istenen limitasyonları sağlayan en düşük kütleye sahip grafik verisi elde edilmiştir.

\subsection{Doğrusal statik analiz bulgulart}


Doğrusal statik analiz sonucunda en yüksek yer değiştirme miktarı $0,16 \mathrm{~mm}$ olarak ölçülmüştür. En yüksek von mises gerilmesi ise 116,62 MPa'dır. Bu gerilme değeri kullanılarak hesaplanan en düşük emniyetli bölgedeki emniyet katsayısı değeri 2,13'tür.

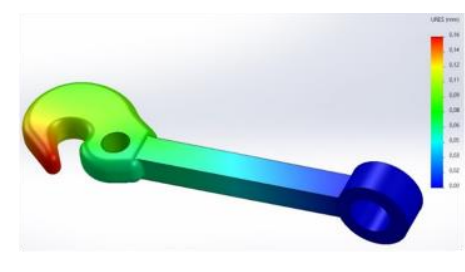

En fazla yer değiştirme: $\mathbf{0 , 1 6} \mathbf{~ m m}$

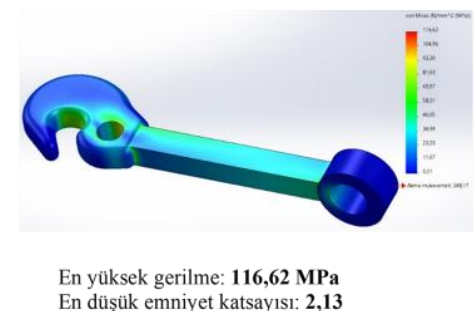

En düșük emniyet katsayısı: 2,13

Şekil 5. Doğrusal statik analiz sonuçları

\subsection{Topoloji optimizasyonu bulgulart}

Doğrusal statik analiz sonucu elde edilen 2,13 değeri dikkate alınarak 2 emniyet katsayısını ve diğer limitasyonları sağlayacak şekilde kütleyi hafifletme hedefiyle topoloji optimizasyonu etüdü uygulanmış ve sonucunda elde edilen .stl uzantılı grafik verisi SOLIDWORKS modelleme ortamında tersine mühendislik işlemine tabi tutulmuştur. Son olarak ortaya çıkan katı modele dökme karbon çeliği malzemesi tanımlanmış ve kütle değeri $26,73 \mathrm{~kg}$ olarak görülmüştür. Topoloji optimizasyonu sonuçları Şekil 6'da gösterilmiştir.

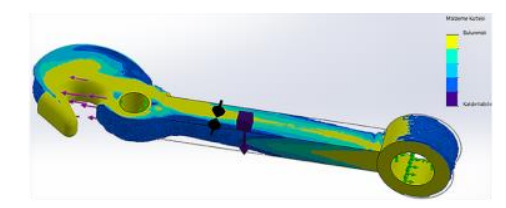

Topoloji optimizasyonu sonucu

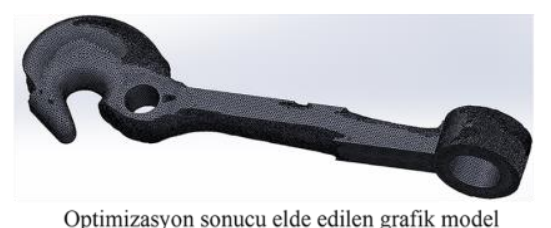

Optimizasyon sonucu elde edilen grafik model

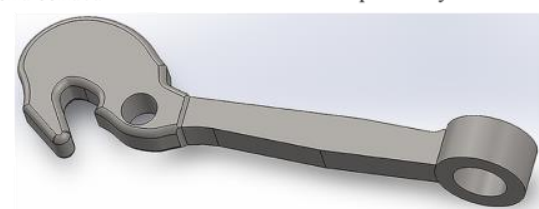

Grafik modelden tersine mühendislik ile elde edilen katı model

Şekil 6. Topoloji optimizasyonu sonuçları

\section{Sonuç}

Teknoloji, üretim ve bilgisayar destekli mühendislik alanlarında gerçekleşen gelişmeler geometrik ve yapısal olarak geleneksel yöntemler ile üretilmesi mümkün olmayan tasarımlara ait ürünlerin üretilebilmesine olanak sağlamıştır. Bu gelişmeler ile ortaya çıkan eklemeli imalat gibi yöntemler sıklıkla kullanılan yöntemler arasındadır. Ortaya çıkan bu geniş çalışma alanı ile ekipmanların ağılık, hacim, doğal frekans, yer değiştirme ve reaksiyon kuvvetlerine göre en uygun olacak modelin tasarlanmasına olanak sağlamaktadır. En uygun yapısal özelliklerin belirlenebilmesi için boyut optimizasyonu, şekil optimizasyonu ve topoloji optimizasyonu yöntemleri sıklıkla kullanılmaktadır. Bu yöntemler içerisinde topoloji optimizasyonu analizi gerçekleştirilen ekipmanın ilk şeklinden tamamen bağımsız olarak analizi gerçekleştirmekte olması nedeniyle çok daha verimli sonuçlar elde edilmesine olanak sağlamaktadır. Topoloji optimizasyonu, yoğunluk tabanlı yöntem, evrimsel yapısal optimizasyon ve seviye seti yöntemleri gibi farklı yöntemler ile gerçekleştirilmektedir. Çalışmamızda sıklıkla kullanılmakta olan yoğunluk tabanlı yöntemden türetilmiş simp yöntemi kullanılarak topoloji optimizasyonu gerçekleştirilmiştir. 
Uygulamada doğrusal statik analiz ve topoloji optimizasyonu SW Simulation sonlu elemanlar analizi paket programı kullanılarak gerçekleştirilmiştir. Analizi gerçekleştirilen ekipmanın teknik detayları EN 15566 Cer kancası tertibatlı koşum takımı standardına göre belirlenmiş ve EN 10083 standardına göre; $200 \mathrm{GPa}$ elastikiyet modülü, 0,32 poisson oranı, 248,17 MPa akma dayanımı ve $7800 \mathrm{~kg} / \mathrm{m}^{3}$ yoğunluk değerlerine sahip olan dökme karbon çeliği malzemesi seçilmiştir. Literatürde yapılan çalışmalarda kanca kavramalı cer takımının $1000 \mathrm{kN}$ dayanım değerine sahip olması gerektiği belirlenmiş ve sistemin tek bir parçası incelendiğinden literatürdeki topoloji optimizasyonu uygulamaları baz alınarak en düşük emniyet katsayısı 2 olacak şekilde $100 \mathrm{kN}$ dayanım değeri uygulanmıştır. Doğrusal statik analiz sonucunda $0,16 \mathrm{~mm}$ en yüksek yer değiştirme ve 116,62 $\mathrm{MPa}$ von mises gerilmesi ölçülmüştür. Bu çalışma yeterli emniyet katsayısını sağlayarak geometriyi hafifletme hedefiyle gerçekleştirildiği için reaksiyon kuvvetleri ve doğal frekanslar dikkate alınmamıştır. Von mises gerilmesine göre 2,13 hesaplanan emniyet katsayısının 2 değerine sahip olması yeterli kabul edilmiş ve bu kısıta göre gerçekleştirilen topoloji optimizasyonu sonucunda istenen dayanım değerlerini ve üretim limitasyonlarını sağlayan hafif model elde edilmiştir.

Başlangıçta 29,16 kg olarak yazılım tarafindan hesaplanan cer kancası ekipmanı, optimizasyon uygulandıktan sonra 26,73 kg'a düşerek toplamda \%8,33 oranında kütlesel kazanım elde edilmiştir. Topoloji optimizasyonu uygulanan modelin mevcut modelin yerini alması için dikkate değer bir kazanım sağlanması gerekmektedir. Üretim yöntemlerindeki zorluklar ve maliyet bu konudaki temel kısıt olarak karşımıza çıkmaktadır. Literatürdeki uygulamalar incelendiğinde, bu gibi sade karbon çeliğinden imal edilen döküm parçalarda, ortaya çıkan kütlesel kazanımın tasarım ve üretim akışını değiştirmeye ve yeni ürünü devreye almaya değer görülmesi için yaklaşık \%30 tasarruf sağlaması gerektiği görülmüştür. Mevcut uygulama yapısı ile kanca kavramalı cer takımı içerisinde bulunan cer kancası ekipmanı için topoloji optimizasyonu uygulaması yapılarak üretim değişikliğine gidilmesi gerekmediği tespit edilmiştir. Yapılan çalışma sonrası, diğer koşum takımı türleri üzerinde gerekli uygulamaların yapılmasının, ayrıca taşıtın dinamik hareket gösterdiği durumlar da göz önüne alınarak eksenel çift yönlü kuvvetlere maruz kalan yapıların farklı yük durumları ile yapısal optimizasyon çalışmalarının yapılması literatür için faydalı olacaktır.

\section{Kaynakça}

[1] J. N. Varandas, A. Paixão, E. Fortunato, B. Zuada Coelho, ve P. Hölscher, "Long-term deformation of railway tracks considering train-track interaction and non-linear resilient behaviour of aggregates - a 3D FEM implementation," Comput. Geotech., c. 126, s. 103712, Eki. 2020, doi: 10.1016/j.compgeo.2020.103712.

[2] W. Ferdous, A. Manalo, G. Van Erp, T. Aravinthan, ve K. Ghabraie, "Evaluation of an innovative composite railway sleeper for a narrow-gauge track under static load," J. Compos. Constr., c. 22, sy 2, s. 04017050, 2018.

[3] S. Kaewunruen, T. Lewandrowski, ve K. Chamniprasart, "Dynamic responses of interspersed railway tracks to moving train loads," Int. J. Struct. Stab. Dyn., c. 18, sy 01, s. 1850011, 2018.

[4] M. Yazdani ve P. Azimi, "Assessment of railway plain concrete arch bridges subjected to high-speed trains," içinde Structures, 2020, c. 27, ss. 174-193.

[5] C. Yang ve Q. M. Li, "Structural optimisation for the collapse zone of a railway vehicle," Int. J. Mech. Sci., c. 165, s. 105201, Oca. 2020, doi: 10.1016/j.ijmecsci.2019.105201.

[6] P. K. Srivastava ve S. Shukla, "Reducing Weight of Freight Bogie Bolster Using Topology Optimization," Rev. GEINTEC-GESTAO INOVACAO E Tecnol., c. 11, sy 3, ss. 324-339, 2021.

[7] C.-S. Kim ve J. M. Kim, "A Study on the Durability Improvement of the Connection Passage Assembly for Railway Vehicles," içinde 2019 IEEE 10th International Conference on Mechanical and Aerospace Engineering (ICMAE), 2019, ss. 518-522.

[8] K. Tajs-Zielińska ve B. Bochenek, "Multi-Domain and Multi-Material Topology Optimization in Design and Strengthening of Innovative Sustainable Structures," Sustainability, c. 13, sy 6, Art. sy 6, Oca. 2021, doi: 10.3390/su13063435. 
[9] H. Völkl, D. Klein, M. Franz, ve S. Wartzack, “An efficient bionic topology optimization method for transversely isotropic materials," Compos. Struct., c. 204, ss. 359-367, Kas. 2018, doi: 10.1016/j.compstruct.2018.07.079.

[10] F. Mezzadri, V. Bouriakov, ve X. Qian, "Topology optimization of self-supporting support structures for additive manufacturing," Addit. Manuf., c. 21, ss. 666-682, May. 2018, doi: 10.1016/j.addma.2018.04.016.

[11] R. Ulewicz, F. Novỳ, P. Novák, ve P. Palček, "The investigation of the fatigue failure of passenger carriage draw-hook," Eng. Fail. Anal., c. 104, ss. 609-616, 2019.

[12] S. M. zadeh Noughabi, K. Dehghani, ve M. Pouranvari, "Failure analysis of automatic coupler SA-3 in railway carriages," Eng. Fail. Anal., c. 14, sy 5, ss. 903-912, 2007.

[13] E. V. Rosa, L. Rios, ve V. Queral, "Progress on the interface between UPP and CPRHS (Cask and Plug Remote Handling System) tractor/gripping tool for ITER," Fusion Eng. Des., c. 88, sy 9-10, ss. 2168-2172, 2013.

[14] O. C. Zienkiewicz, R. L. Taylor, P. Nithiarasu, ve J. Z. Zhu, The finite element method, c. 3. McGrawhill London, 1977.

[15] J. N. Reddy, Introduction to the finite element method. McGraw-Hill Education, 2019.

[16] L. J. Segerlind ve H. Saunders, “Applied finite element analysis,” 1987.

[17] D. V. Hutton, Fundamentals of finite element analysis. McGraw-hill, 2004.

[18] B. C. L. Vanam, M. Rajyalakshmi, ve R. Inala, "Static analysis of an isotropic rectangular plate using finite element analysis (FEA)," J. Mech. Eng. Res., c. 4, sy 4, ss. 148-162, 2012.

[19] S. E. Benzley, E. Perry, K. Merkley, B. Clark, ve G. Sjaardama, "A comparison of all hexagonal and all tetrahedral finite element meshes for elastic and elasto-plastic analysis," içinde Proceedings, 4th international meshing roundtable, 1995, c. 17, ss. 179-191.

[20] E. Carrera, M. Cinefra, M. Petrolo, ve E. Zappino, Finite element analysis of structures through unified formulation. John Wiley \& Sons, 2014.

[21] M. E. Botkin ve H.-P. Wang, "An adaptive mesh refinement of quadrilateral finite element meshes based upon a posteriori error estimation of quantities of interest: linear static response," Eng. Comput., c. 20 , sy 1 , ss. $31-37,2004$.

[22] T. J. Hughes, The finite element method: linear static and dynamic finite element analysis. Courier Corporation, 2012.

[23] L. Meng vd., "From Topology Optimization Design to Additive Manufacturing: Today's Success and Tomorrow's Roadmap," Arch. Comput. Methods Eng., c. 27, sy 3, ss. 805-830, Tem. 2020, doi: 10.1007/s11831-019-09331-1.

[24] J. Zhu, H. Zhou, C. Wang, L. Zhou, S. Yuan, ve W. Zhang, “A review of topology optimization for additive manufacturing: status and challenges," Chin. J. Aeronaut., 2020.

[25] K. Mhapsekar, M. McConaha, ve S. Anand, "Additive Manufacturing Constraints in Topology Optimization for Improved Manufacturability,” J. Manuf. Sci. Eng., c. 140, sy 5, May. 2018, doi: 10.1115/1.4039198.

[26] S. N. Reddy K, I. Ferguson, M. Frecker, T. W. Simpson, ve C. J. Dickman, "Topology optimization software for additive manufacturing: A review of current capabilities and a real-world example," içinde International Design Engineering Technical Conferences and Computers and Information in Engineering Conference, 2016, c. 50107, s. V02AT03A029.

[27] T. Zhan, "Progress on different topology optimization approaches and optimization for additive manufacturing: a review," J. Phys. Conf. Ser., c. 1939, sy 1, s. 012101, May. 2021, doi: 10.1088/17426596/1939/1/012101.

[28] J. Wu, O. Sigmund, ve J. P. Groen, “Topology optimization of multi-scale structures: a review," Struct. Multidiscip. Optim., c. 63, sy 3, ss. 1455-1480, Mar. 2021, doi: 10.1007/s00158-021-02881-8.

[29] J. Gao, M. Xiao, Y. Zhang, ve L. Gao, "A Comprehensive Review of Isogeometric Topology Optimization: Methods, Applications and Prospects," Chin. J. Mech. Eng., c. 33, sy 1, s. 87, Kas. 2020, doi: 10.1186/s10033-020-00503-w.

[30] B. Yunfei, C. Ming, ve L. Yongyao, "Structural topology optimization for a robot upper arm based on SIMP method," içinde Advances in Reconfigurable Mechanisms and Robots II, Springer, 2016, ss. 725-733.

[31] S. Zhang, H. Li, ve Y. Huang, "An improved multi-objective topology optimization model based on SIMP method for continuum structures including self-weight," Struct. Multidiscip. Optim., c. 63, sy 1, ss. 211-230, Oca. 2021, doi: 10.1007/s00158-020-02685-2.

[32] H. S. Gebremedhen, D. E. Woldemicahel, ve F. M. Hashim, “Three-dimensional stress-based topology optimization using SIMP method,” Int. J. Simul. Multidiscip. Des. Optim., c. 10, s. A1, 2019. 
[33] V. Kandemir, O. Dogan, ve U. Yaman, "Topology optimization of 2.5D parts using the SIMP method with a variable thickness approach," Procedia Manuf., c. 17, ss. 29-36, Oca. 2018, doi: 10.1016/j.promfg.2018.10.009.

[34] W. Zuo ve K. Saitou, "Multi-material topology optimization using ordered SIMP interpolation," Struct. Multidiscip. Optim., c. 55, sy 2, ss. 477-491, 2017.

[35] E. Standards, "UNE EN 15566:2017 Railway applications - Railway rolling stock - Draw gear and screw coupling," https://www.en-standard.eu. https://www.en-standard.eu/une-en-15566-2017railway-applications-railway-rolling-stock-draw-gear-and-screw-coupling/ (erişim Eki. 29, 2021).

[36] "EN 10083-1:2006 - Steels for quenching and tempering - Part 1: General technical delivery conditions," iTeh Standards Store. https://standards.iteh.ai/catalog/standards/cen/bf8239bb-e51540b3-a79f-5ffdb0c3e7a6/en-10083-1-2006 (erişim Eki. 29, 2021).

[37] "EN 10083-2:2006 - Steels for quenching and tempering - Part 2: Technical delivery conditions for non alloy steels," iTeh Standards Store. https://standards.iteh.ai/catalog/standards/cen/753c07e818e1-4904-83ae-fec50f911beb/en-10083-2-2006 (erişim Eki. 29, 2021).

[38] F. Nový, M. Jambor, M. Petrů, L. Trško, S. Fintová, ve O. Bokůvka, "Investigation of the brittle fracture of the locomotive draw hook," Engineering Failure Analysis, c. 105, ss. 305-312, Kas. 2019, doi: 10.1016/j.engfailanal.2019.07.019

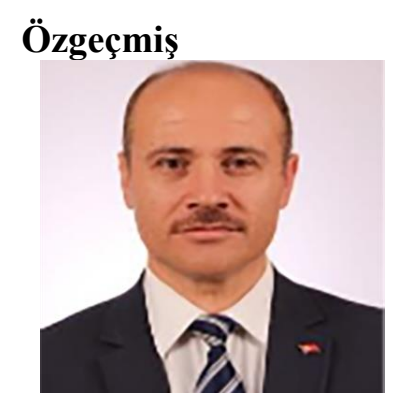

\section{Cevat ÖZARPA}

Karabük Üniversitesi Makine Mühendisliği Bölümünde Doktor Öğretim Üyesi olarak çalışmaktadır. Lisans eğitimini Gaziantep Üniversitesi’nde, Yüksek Lisansını İstanbul Teknik Üniversitesi'nde, Doktorasını Sakarya Üniversitesi'nde Makine Mühendisliği ve Doktora sonrası çalışmalarını ABD'de Virginia Commonwealth Üniversitesi Makine Mühendisliği Tasarım Üretim Laboratuvarı'nda tamamlamıştır. Evli ve 5 çocuk babasıdır.

E-Posta: cevatözarpa@karabuk.edu.tr

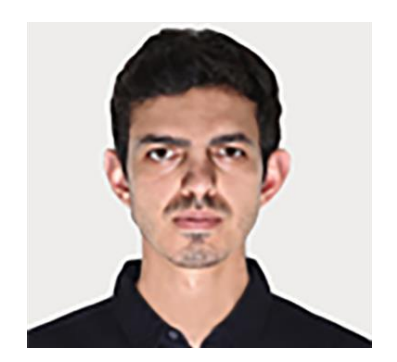

\section{Hüseyin BOTSALI}

Marmara Üniversitesi Makine Mühendisliği bölümünde araştırma görevlisi olarak çalışmaktadır. Lisans eğitimini Gazi Üniversitesi İmalat Mühendisliğinde tamamlamıştır. Yüksek lisansına Karabük Üniversitesi Makine Mühendisliğinde devam etmektedir. Evlidir.

E-Posta: huseyinbotsali@gmail.com

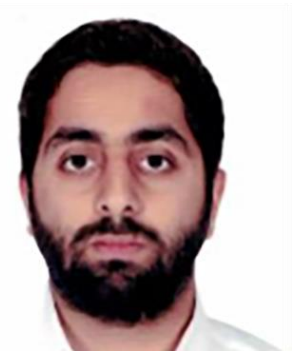

\section{Bahadır Furkan KINACI}

Karabük Üniversitesi Raylı Sistemler bölümünde Öğretim Görevlisi olarak çalışmaktadır. Lisans eğitimini Karabük Üniversitesi Raylı Sistemler Mühendisliği bölümünde Yüksek Lisans eğitimini Sivas Cumhuriyet Üniversitesi Makine Mühendisliği bölümünde tamamlamıştır. Doktora eğitimine Karabük Üniversitesi Makine Mühendisliğinde devam etmektedir. Evlidir.

E-Posta: furkankinaci@karabuk.edu.tr

\section{Beyanlar:}

Bu makalede bilimsel araştırma ve yayın etiğine uyulmuştur.

Yazarların katkıları:

Cevat ÖZARPA: Kavramsallaştırma, Metodoloji, Doğrulama, Kontrol, Yazma-gözden geçirme ve düzenleme. Hüseyin BOTSALI: Doğrulama, İnceleme, Yazılım uygulaması, Yazma-gözden geçirme ve düzenleme. Bahadır Furkan KINACI: Kaynaklar, Görselleştirme, Yazma-orijinal taslak hazırlama, Yazma-gözden geçirme ve düzenleme. 